\title{
PENGEMBANGAN Sistem EVALUASI AKADEMIK BERDASARKAN PREDIKAT NILAI INDEKS PRESTASI MAHASISWA
}

\author{
Intan Nur Farida ${ }^{1)}$, Miftakhul Maulidina ${ }^{2)}$ \\ ${ }^{1)}$ Teknik Informatika Universitas Nusantara PGRI Kediri \\ ${ }^{2)}$ Teknik Elektro Universitas Nusantara PGRI Kediri \\ e-mail: in.nfarida@gmail.com ${ }^{1)}$, miftakhulmaulidi@unpkediri.ac.id ${ }^{2)}$
}

\begin{abstract}
Prestasi mahasiswa secara akademik terdapat pada nilai hasil studi tiap akhir semester. Hasil studi menampilkan predikat nilai sesuai indeks prestasi kumulatif. Adapun predikat nilai prestasi mahasiswa mulai tertinggi antara lain cumlaude, sangat memuaskan dan memuaskan. Banyaknya mahasiswa yang lulus terlambat dari aturan pedoman akademik maka perlu dilakukan pengembangan sistem berbasis komputer untuk mengevaluasi prestasi mahasiswa. Penelitian ini bertujuan agar mengetahui hasil perkiraan masa studi mahasiswa sesuai dengan pedoman akademik universitas atau terlambat berdasarkan predikat nilai indeks prestasi mahasiswa. Metode yang digunakan pada penelitian ini adalah nä̈ve bayes dengan menghasilkan status kelulusan sesuai dan terlambat. Penelitian ini menunjukkan akurasi sebesar 70\% dengan membandingkan hasil perhitungan sistem dengan data yudisium pada kenyataan.
\end{abstract}

Kata Kunci-predikat nilai indeks prestasi, prestasi hasil studi, naive bayes

\section{PENDAHUluan}

$\mathrm{N}$ ilai akademik mahasiswa ditunjukkan pada kartu hasil studi mahasiswa yang diperoleh stiap akhir semester. Kartu hasil studi menunjukkan rekapitulasi nilai setiap matakuliah yang ditempuh selama satu semester. Terdapat pula nilai indeks prestasi yang diperoleh dari perkalian bobot sks dengan nilai angka tiap matakuliah yang selanjutnya dijumlahkan untuk seluruh matakuliah yang dijalani selama satu semester dan dihitung rata-rata sehingga diperoleh nilai indeks prestasi kumulatif pada semester tertentu.

Adanya kebutuhan informasi perkiraan masa studi mahasiswa untuk mengetahui solusi langkah akademik karena banyaknya mahasiswa lulus dengan masa studi yang lama dan lebih dari waktu ideal pada pedoman akademik universitas.

Predikat nilai indeks prestasi mahasiswa terdiri dari nilai yang tertinggi adalah cumlaude (dengan pujian), sangat memuaskan dan memuaskan. Penelitian ini menunjukkan perkiraan masa studi mahasiswa berdasarkan predikat tersebut. Perkiraan masa studi ditunjukkan dengan status sesuai pedoman akademik universitas dan terlambat.

Selain menggunakan atribut predikat nilai indeks prestasi kumulatif terdapat atribut jenis kelamin, asal sekolah, asal kota, pekerjaan orag tua dan penghasilannya. Masing-masing data mahasiswa akan dihitung nilai probabilitasnya untuk mengetahui perkiraan masa studi mahasiswa.

Prediksi Masa Studi Mahasiswa dengan Menggunakan Algoritma Naïve Bayes telah mengkategorikan masa studi mahasiswa dengan tepat waktu, terlambat dan tidak lulus [1]. Sedangkan Data Mining untuk Evaluasi Kinerja Akademik Mahasiswa Menggunakan Algoritma Naive Bayes Classifier menunjukkan semakin banyak data training yang digunakan maka tingkat Recall, Precision dan Accuracion sistem akan semakin baik [2].

Penerapan Data Mining Untuk Evaluasi Kinerja Akademik Mahasiswa Di Universitas Klabat Dengan Metode Klasifikasi menggunakan metode C 4.5 menunjukkan bahwa Untuk mencapai semester akhir dalam 4 tahun seorang mahasiswa diawal semester berdasarkan pohon keputusan yang terbentuk yaitu 
mahasiswa yang mempunya indeks prestasi 3.5 - 3.87 (magda) serta penempatan bahasa inggris yang berada pada level adv dan inter [3].

Penelitian ini bertujuan untuk memberikan informasi perkiraan masa studi mahasiswa di Fakultas teknik Universitas Nusantara PGRI Kediri khususnya pada program studi Sistem Informasi, Teknik Mesin dan Teknik Informatika. Sebagai bentuk evaluasi prestasi mahasiswa berdasarkan predikat nilai indeks prestasi yang ditunjukkan pada setiap semester.

\section{Metode PENELITIAN}

\section{A. Studi Literatur}

Data mining merupakan kegiatan menggunakan teknik matematika, kecerdasan buatan dan machine learning untuk mengidentifikasi informasi yang berguna dan pengetahuan terkait dari database berukuran besar [4]. Pemanfaatan data mining secara deskriptif yaitu mencari pola yang bermanfaat dalam menguraikan karakteristik data dan secara prediktif melaksanakan perkiraan berdasarkan model pengetahuan [5].

Naïve Bayes adalah teknik prediksi yang berdasarkan probabilistik sederhana yang mengacu pada penerapan teorema Bayes dengan asumsi ketidaktergantungan yang kuat [6].

$$
P(Y \mid H)=\frac{P(Y \mid H) P(H)}{P(Y)}
$$

\footnotetext{
Keterangan:

$Y \quad=$ bukti

$H \quad=$ hipoteses

$P(H \mid Y)=$ probabilitas bahwa hipotesis $\mathrm{H}$ benar untuk bukti $\mathrm{Y}$, dengan arti $\mathrm{P}(\mathrm{Y} \mid \mathrm{H})$ merupakan probabilitas posterior $\mathrm{H}$ dengan syarat $\mathrm{Y}$.

$P(Y \mid H) \quad=$ probabilitas bahwa bukti $\mathrm{Y}$ benar untuk hipotesis $\mathrm{H}$, yaitu proabilitas posterior $\mathrm{X}$ dengan syarat $\mathrm{H}$.

$P(H) \quad=$ probabilitas prior hipotesis $\mathrm{H}$

$P(Y) \quad=$ probabilitas prior bukti $\mathrm{Y}$
}

Penggunaan atribut pada penelitian ini antara lain: jenis kelamin, alamat (kota), SMA asal, pekerjaan orang tua, jumlah penghasilan, program studi, predikat nilai indeks prestasi semester 1 sampai 4, nilai Indeks Prestasi Kumulatif semester 4. Sedangkan predikat nilai indeks prestasi mahasiswa yang diterapkan antara lain sesuai tabel 1 .

TABEL I

PREDIKAT NiLAi INDEKS PRESTASI

\begin{tabular}{cc}
\hline \hline Indeks Prestasi & Predikat \\
& \\
\hline $3,51-4,00$ & Dengan Pujian (Cum Laude) \\
$2,76-3,50$ & Sangat Memuaskan \\
$2,00-2,75$ & Memuaskan \\
\hline \hline
\end{tabular}

\section{B. Identifikasi Kebutuhan Data}

Data yang digunakan terdiri dari data training dan data testing. Data training menggunakan data mahasiswa yang telah yudisium yaitu angkatan 2010, 2011, 2012 dan 2013. Sedangkan data testing merupakan data mahasiswa aktif angkatan 2014. 


\section{Desain Sistem}

Perancangan sistem menggunakan notasi Unified Modelling Language (UML).

D. Implementasi (Pemrograman)

Penerapan desain sistem menjadi suatu sistem berbasis komputer menggunakan bahasa pemrograman java dan database mySQL.

\section{HASIL DAN PEMBAHASAN}

\section{A. Analisis Hasil}

M Perhitungan untuk mengetahui masa studi mahasiswa sebagai evaluasi kegiatan akademik antara lain menggunakan data training berupa nilai alumni tahun angkatan 2010, 2011 dan 2012. Sedangkan data testing yaitu data yang menjadi target adalah nilai mahasiswa angkatan 2014.

Misalkan terdapat data target jenis kelamin Perempuan, berasal dari Kediri, berasal dari SMK, pekerjaan orang tua wiraswasta dengan penghasilan antara 1sampai 2 juta, dari program studi Teknik Informatika, dengan nilai IP semester 1 sampai 4 adalah Cumlaude, Sangat memuaskan, Cumlaude, Cumlaude, sedangkan nilai IPK terakhir adalah Cumlaude.

Perhitungan sederhana menggunakan algoritma naive bayes antara lain:

1) Menentukan kelas keputusan yaitu sesuai (C1) dan terlambat (C2). Selanjutnya menghitung probabilitas prior untuk kelas $\mathrm{C} 1$ dan $\mathrm{C} 2$.

$P($ masastudi $=$ sesuai $)=0,34$

$P($ masastudi=terlambat $)=0,66$

2) Menghitung probabilitas bersyarat untuk setiap kelas $\mathrm{P}(\mathrm{Y} \mid \mathrm{C}), \mathrm{i}=1,2$ dan untuk setiap atribut. Nilai probabilitas masing-masing atribut ditunjukkan pada tabel 2.

TABEL II

Nilai Probabilitas SETIAP ATRIBUT

\begin{tabular}{cllll}
\hline \hline No & Atribut & Kriteria Target & P (s) & P (t) \\
\hline 1 & JK & P & 0.18 & 0.21 \\
2 & asalkota & Kediri & 0.59 & 0.33 \\
3 & asalsma & SMK & 0.47 & 0.36 \\
4 & kerjaortu & Wiraswasta & 0.41 & 0.42 \\
5 & gajiortu & Antara 1-2 juta & 0.24 & 0.55 \\
6 & prodi & TI & 0.59 & 0.12 \\
7 & nips1 & C & 0.12 & 0.06 \\
8 & nips2 & S & 0.82 & 0.70 \\
9 & nips3 & C & 0.12 & 0.06 \\
10 & nips4 & C & 0.06 & 0.06 \\
11 & nipk & C & 0.18 & 0.06 \\
\hline \hline
\end{tabular}

Keterangan:

JK : jenis kelamin

asalkota : alamat kota asal

asalsma : asal SMK/ sederajat

kerjaortu : pekerjaan orang tua

gajiortu : penghasilan orang tua per bulan

prodi : program studi

nips : nilai indeks prestasi 

C : cumlaude
$\mathrm{S} \quad$ : sangat memuaskan
M : memuaskan
nipk : nilai indeks prestasi kumulatif
$\mathrm{P}(\mathrm{s}) \quad$ : probabilitas sesuai
$\mathrm{P}(\mathrm{t}) \quad$ : probabilitas terlambat

3) Hitung probabilitas $\mathrm{P}(\mathrm{Y} \mid \mathrm{Ci}) \mathrm{P}(\mathrm{Ci})$ untuk setiap kelas $\mathrm{Ci}$, yaitu:

$P(Y \mid$ masastudi $=$ sesuai $)=P(J K) \times P($ asalkota $) \times P($ asalsma $) \times P($ kerjaortu $) \times P($ gajiortu $) \times P($ prodi $) \times$ $P$ (nips1) $\times P$ (nips2) $\times P$ (nips3) $\times P$ (nips4) $\times P($ nipk $)=3,2941 \times 10^{-7}$

$P(Y \mid$ masastudi $=$ terlambat $)=P(J K) \times P($ asalkota $) \times P($ asalsma $) \times P($ kerjaortu $) \times P($ gajiortu $) \times$

$P$ (prodi) $x P$ (nips1) $\times P$ (nips2) $\times P$ (nips3) $\times P$ (nips4) $\times P($ nipk $)=6,8552 \times 10^{-9}$

4) Probabilitas posterior bahwa tuple $Y$ berada di kelas Ci dengan memaksimalkan $\mathrm{P}(\mathrm{Y} \mid \mathrm{Ci}) \mathrm{P}(\mathrm{Ci})$, untuk i

$=1,2$.

$\mathrm{P}(Y \mid$ masastudi $=$ sesuai $) \times P($ masastudi $=$ sesuai $)=3,2941 \times 10^{-7} \times 0,34=1 \times 10^{-7}$

$P(Y \mid$ masastudi $=$ terlambat $) \times P($ masastudi $=$ terlambat $)=6,8552 \times 10^{-9} \times 0,66=5 \times 10^{-9}$

5) Membandingkan hasil perhitungan untuk kelas sesuai dengan kelas terlambat.

Hasil perhitungan menunjukkan kelas sesuai lebih besar daripada kelas terlambat, sehingga

kesimpulan hasil masa studi adalah sesuai. Sebagaimana ditunjukkan pada gambar 1.

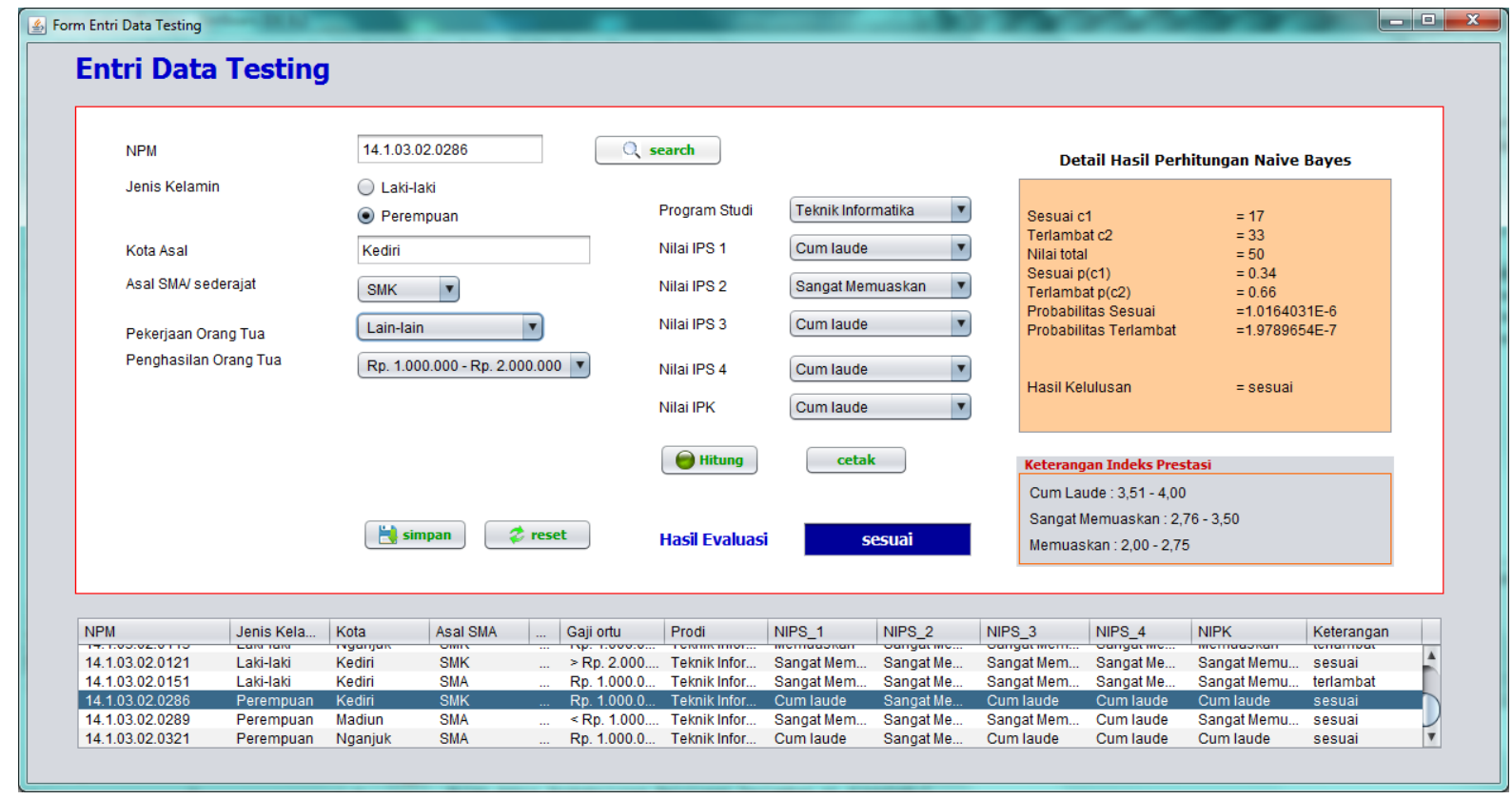

Gambar 1. Tampilan untuk perhitungan data testing

\section{B. Evaluasi Hasil}

Evaluasi hasil dilakukan dengan melakukan perbandingan hasil perhitungan yang ditunjukkan oleh sistem dengan hasil pada kenyataan. Yaitu hasil perhitungan menggunakan naïve bayes yang diperoleh dari sistem dibandingkan dengan data hasil studi mahasiswa pada yudisium. Data mahasiswa yang menjadi target adalah mahasiswa angkatan 2014 dengan membandingkan data yudisium periode semester Genap 2017/2018. Data yang digunakan menggunakan sepuluh mahasiswa dari program studi Teknik Informatika tahun masuk 2014. Hasil perbandingan ditunjukkan pada tabel 3. 
TABEL III

PERBANDINGAN HASIL SISTEM DENGAN DATA YUDISIUM

\begin{tabular}{cclcc}
\hline \hline NPM & \multicolumn{1}{c}{ Prodi } & Hasil Sistem & Data Yudisium & Kesimpulan \\
\hline$\ldots 0034$ & Teknik Informatika & sesuai & ada & valid \\
$\ldots 0079$ & Teknik Informatika & terlambat & tidak & valid \\
$\ldots 0082$ & Teknik Informatika & sesuai & tidak & tidak valid \\
$\ldots 0106$ & Teknik Informatika & sesuai & tidak & tidak valid \\
$\ldots 0113$ & Teknik Informatika & terlambat & tidak & valid \\
$\ldots 0121$ & Teknik Informatika & sesuai & tidak & tidak valid \\
$\ldots 0151$ & Teknik Informatika & terlambat & tidak & valid \\
$\ldots 0286$ & Teknik Informatika & sesuai & ada & valid \\
$\ldots 0289$ & Teknik Informatika & sesuai & ada & valid \\
$\ldots 0321$ & Teknik Informatika & sesuai & ada & valid \\
\hline \hline
\end{tabular}

Keterangan:

Hasil sistem menyatakan sesuai mempunyai makna bahwa masa studi mahasiswa tersebut dapat diselesaikan tepat empat tahun yang artinya sesuai dengan pedoman akademik universitas. Sedangkan terlambat menyatakan bahwa masa studi mahasiswa tidak sesuai dengan aturan pada pedoman akademik.

Pada hasil kesimpulan tabel 3 menunjukkan 70\% valid dan $30 \%$ tidak. Hal ini membuktikan bahwa sistem dapat memberikan hasil evaluasi akademik berdasarkan predikat nilai indeks prestasi mahasiswa dengan memperkirakan masa studi mahasiswa dalam menyelesaikan perkuliahan. Hasil perkiraan dapat dijadikan bahanpertimbangan bagi mahasiswa maupun dosen pembimbing akademik untuk memberikan solusi penyelesaian studi mahasiswa.

\section{Kesimpulan}

Pengembangan sistem evaluasi akademik berdasarkan predikat nilai indeks prestasi mahasiswa telah menunjukkan perkiraan masa studi mahasiswa. Hasil dari sistem dapat digunakan oleh mahasiswa untuk mempersiapkan sejak awal jika menunjukkan perkiraan terlambat. Berdasarkan hasil uji maka sistem dapat diterapkan dengan akurasi hasil perbandingan dengan data yudisium sebesar 70\%.

Saran untuk penelitian selanjutnya adalah menggunakan metode dan algoritma yang berbeda dan dapat dilakukan juga menggabungkan dua algoritma sekaligus. Sedangkan untuk mengetahui tingkat akurasi yang lebih dapat dilaksanakan beberapa scenario uji coba data yang digunakan.

\section{DAFTAR PUSTAKA}

[1] Amelia, M.W, Arie S. M. Lumenta, Agustinus Jacobus, Prediksi Masa Studi Mahasiswa dengan Menggunakan Algoritma Naïve Bayes, E-Journal Teknik Informatika, Vol 11, No.1 (2017) ISSN : $2301-8364$.

[2] Mustafa, M.S, Muh Rizky Ramadhan, Angelina P. Thenata, Implementasi Data Mining untuk Evaluasi Kinerja Akademik Mahasiswa Menggunakan Algoritma Naive Bayes Classifier, Citec Journal, Vol. 4, No. 2, pp. 151-162, Februari 2017 - April 2017.

[3] Mandias, Green Ferry, Penerapan Data Mining Untuk Evaluasi Kinerja Akademik Mahasiswa Di Universitas Klabat Dengan Metode Klasifikasi, dalam Konferensi Nasional Sistem \& Informatika 2015 , p. 351. 
[4] Turban, E., J.E. Aronson dan T.P. Liang, Decision Support System and Intelligent Systems - 7th ed. Pearson Education, Inc. Pearson Education, Inc., 2005, Dwi Prabantini (penterjemah). Sistem Pendukung Keputusan dan Sistem Cerdas, Yogyakarta : ANDI, 2005.

[5] Suyanto, Data Mining Untuk Klasifikasi dan Klasterisasi Data, Bandung: Informatika, 2017.

[6] Prasetyo, Eko, Data Mining Konsep dan Aplikasi Menggunakan MATLAB. Yogyakarta: Andi, 2012. 